\title{
Unusual behaviour of captive-raised gibbons: implications for welfare
}

\author{
Susan M. Cheyne
}

Published online: 16 August 2007

(C) Japan Monkey Centre and Springer 2007

Erratum to: Primates (2006) 47:322-326

DOI 10.1007/s10329-006-0190-z

The original version of this article unfortunately contained a mistake. The "Acknowledgements" section should read:

SMC would like to thank Aurélien Brulé (Chanee), the director of the Kalaweit Project, and all staff who helped with data collection. Also to LIPI, the Indonesian Institute of Science for permission to work in Kalimantan. Funding was provided by The Gibbon Foundation, the C.K. Marr Educational Trust and Downing College, Cambridge. Thanks to Dr. David J. Chivers for comments on a draft of this manuscript.

The online version of the original article can be found under doi:10.1007/s10329-006-0190-z.

S. M. Cheyne ( $\square)$

Wildlife Research Group, Department of Anatomy,

University of Cambridge, Downing Street,

CB2 3DY Cambridge, UK

e-mail: susancheyne76@yahoo.com 